1. Cruickshank, A.R.I. \& Benton M.J. Nature 317, 715-717 (1985).

2. Bonaparte, J.F. Geobios Mem. Sp. 6, 99-112 (1982)

3. Brinkman, D. Breviora 464, 1-23 (1981)

4. Chatterjee, S. Nature 295, 317-320 (1982)

5. Gauthier, J.A. Mem. Calif. Acad. Sci. 8, 1-55 (1986)

6. Parrish, J.M. in 3rd Symp. Mesozoic Terrestrial Ecosyst. Short Pap. (eds Reif, W.E. \& Westphal, F.) 169-173 (Attempto, Tubingen, 1984)

7. Parrish, J.M. Hunteria 1, (2) 1-36 (1986)

8. Cruickshank, A.R.I. S. Afr. J. Sci. 72, 168-178(1979)

SIR-Cruickshank and Benton ${ }^{1}$ reinterpreted the ankle joint of the early archosaur Euparkeria, which they described as having a modified primitive mesotarsal (MPM) joint, rather than the crocodile reversed (CR) joint usually attributed to that $\operatorname{taxon}^{2-5}$. Three other ankle joints are recognized in archosaurs: the ancestral primitive mesotarsal (PM) joint, crocodile normal $(\mathrm{CN})$ and advanced mesotarsal (AM) joints. The evolutionary history of these joints is controversial ${ }^{1-5}$. Cruickshank and Benton did not escape two conceptual errors: (1) they treated homology as if it were an inductive rather than a deductive concept; and (2) they invoked hypothesized evolutionary processes to support their preferred phylogenetic pattern, instead of using the less theory-laden pattern to test hypotheses about evolutionary processes. For the purposes of this argument, the proposition that archosaurs have five different and non-overlapping types of ankle joint is accepted, although this does not appear to be the case ${ }^{4}$.

The first problem stems from Cruickshank and Benton's' assertion that differences between the ankle joints of Euparkeria and Ornithosuchidae (CR) preclude homology. To be homologous, two characters need not be particularly similar, but must derive from a common ancestor $^{6}$. For example, the form and function of the quadrate bone in living mammals is radically different from that of their extinct relatives, but the elements are homologous'. Cruickshank and Benton $^{1}$ admitted that the peg-in-socket ankle joints of Euparkeria and Ornithosuchidae share a derived condition in that the peg is on the calcaneum and the socket is in the astragalus. The shared derived characters that are consistent with the preferred phylogeny are interpreted as homologous, whereas those that are discordant with it are homoplastic ${ }^{8}$. Thus, if Euparkeria and Ornithosuchidae are closely related, the derived resemblance would be most simply explained as homologous, even if their ankle joints are otherwise completely different. Conversely, if they are not, then their ankle joints would be homoplastic, no matter how similar they might be. So the problem reduces to the relationships of Euparkeria: is it the sister group of other archosaurs as Benton suggested $^{9}$, or is it on the ornithosuchian side of the archosaur tree as others have argued $^{2-5}$ ?

The second problem faces all phylo- genetic analyses of archosaur ankle joints. The problem stems from assumptions about evolutionary processes underlying the ordering of states in a multistate character, which can be illustrated as follows. Characters having two states, an ancestral condition $(0)$ and one derived therefrom (1), are termed binary characters and minimally they imply one evolutionary transformation and specify a single character tree. But even the minimum number of possible character trees rises dramatically with an increasing number of states. For example, a three-state character (two transformations) yields three equally parsimonious character trees $[(0-1-2),(0-2-$ $1)$, or $(0-1$ and $0-2)]$, and a four-state character (three transformations) yields 16 , and so on. Given that the archosaur ankle joint has five states - $0(\mathrm{PM})$, 1(MPM), 2(CN), 3(CR) and 4(AM) numerous character trees, all with a minimum of four transformations, are possible. An unambiguous basis ${ }^{10}$ for choosing one among these alternatives requires addition of more taxa and binary characters. That is, to conclude that state 0 transformed into state 1 and then into 2 , for example, there must be at least four taxa ( $=2 \times$ number of transformations) and two binary characters $(=2 \times$ number of transformations -2 ), arrayed in the phylogeny $(0(1(12)))$. Thus, demonstrating a linear evolutionary sequence among archosaur ankle joints requires a minimum of eight taxa and six binary characters. This reduces to a problem of evolutionary rates; characters that evolve less rapidly (binary) provide a clearer picture of phylogeny than do characters that evolve more rapidly (multistate). An archosaur phylogeny derived from binary characters will probably tell us more about the evolution of archosaur ankle joints than the ankle joints will be able to tell us about archosaur phylogeny.

\section{Department of Herpetology,}

J.A. Gauthier

California Academy of Sciences, San Francisco, California 94118, USA

1. Cruickshank, A.R.I. \& Benton M.J. Nature 317, 715-717 (1985)

2. Brinkman, D. Breviora 464, 1-23 (1981).

3. Chatterjee, S. Nature 295, 317-320(1982).

4. Gauthier, J.A. Mem. Calif. Acad. Sci. 8, 1-55 (1986).

Parrish, J.M. Hunteria 1, 1-75 (1986)

6. Hull. D.L. Syst. Zool. 25, 174-191 (1976)

7. de Beer, G. The Development of the Vertebrate Skul (Clarendon, Oxford)

8. Rieppel, O. Z. Zool. Syst. Evol.forsch. 18, 315-319 (1980).

9. Benton, M.J. Zool. J. Linn. Soc. 84, 97-164 (1985)

10. Maddison, W.P., M.J. Donoghue \& D. R. Maddison. Syst. Zool. 33, 83-103 (1984)

CRuickshank AND Benton REPLY-We believe the following may be the points of contention: (1) the nature of the ankle in Euparkeria; (2) the question of homology; and (3) the need to examine as many parts of an animal as possible before coming to decisions about relationships. Above, Parrish illustrates a right ankle of Euparkeria but gives no provenance for it. These tarsal bones differ in detail from those illustrated elsewhere ${ }^{1}$ and the reconstructions are also different. The bones of the ankle in Euparkeria are very small, but seem to be so close to those of Chanaresuchus and in some important respects to that of Erythrosuchus, representatives of thecodontian families which range into the Upper Triassic, that we have to regard them as an independent radiation of the Archosauria.

It would be a neat solution to be able to continue to support the contention that there was an evolutionary gradient leading from Proterosuchus through Euparkeria to Riojasuchus, but if we are to restrict the argument entirely to ankle morphology, then the problem centres on Euparkeria. We have difficulty in correlating the orientation and reconstructed relationships of the Euparkeria ankle bones illustrated by Parrish with those illustrated elsewhere ${ }^{1.2}$. The essential feature of the calcaneum is the retention of a deep, posteriorly directed pyramid, which articulated with the complementary recess in the astragalus. This would allow restricted anteroposterior movement only. This is anatomically and functionally so far removed from the condition in Riojasuchus that we still have great difficulty reconciling the homologies of the two forms. Euparkeria and Riojasuchus may be said to have similar astragalocalcanear articulations - structures shaped like partial cylinders fitting into recesses on the distal faces of astragali but their axes of rotation are at right angles to one another by our interpretation.

Gauthier argues that we have failed to understand the concept of homology. This is a larger question than can be properly answered here, and is not entirely relevant to the original paper ${ }^{3}$. We argued that the ankles of Euparkeria and Riojasuchus are not homologous on the basis of detailed anatomy, and not on the basis of an assumed pattern of evolution. We agree with Gauthier that a phylogeny of archosaurs must be based on an analysis of as many characters as possible, from all parts of the skull and skeleton ${ }^{3}$. Our paper was intended as a commentary on the large numbers of papers that had been published recently on archosaur ankles, not as a final phylogenetic statement.

A.R.I. CRUICKSHANK

72 Thirlmere Road, Hinckley LE10 OPF, Leicestershire, $U K$

\section{M.J. Benton}

Department of Geology,

The Queen's University of Belfast,

Belfast BT7 1NN,

Northern Ireland

1. Cruickshank, A.R.I. S.Afr.J.Sci. 75, 168-178(1979)

. Cruickshank, A.R.I. \& Benton, M.J. Nature 317, 715-717 (1985).

. Benton, M.J. \& Clark, J. in Phylogeny and Classification of the Tetrapods Vol. 1 (ed. Benton, M.J.) (Oxford University Press, in the press). 